\title{
An improved clearing and staining protocol for evaluation of arbuscular mycorrhizal colonisation in darkly pigmented woody roots
}

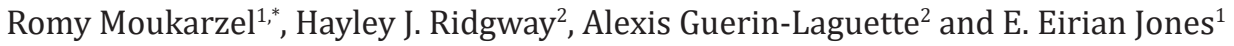 \\ ${ }^{1}$ Lincoln University, Lincoln 7647, Canterbury, New Zealand \\ ${ }^{2}$ The New Zealand Institute for Plant and Food Research Ltd, Lincoln 7608, Canterbury, New Zealand \\ *Corresponding author: romy.moukarzel@lincolnuni.ac.nz \\ (Original submission received 9 March 2020; accepted in revised form 9 November 2020)
}

\begin{abstract}
Arbuscular mycorrhizal fungi (AMF) establish symbiotic interactions with the roots of vascular plants, including grapevines. Verifying AMF colonisation routinely requires establishing the presence of hyphae, arbuscules and vesicles. Clearing roots with potassium hydroxide $(\mathrm{KOH})$ followed by staining with trypan blue has been used previously to visualise fungal structures, however visualisation is difficult with darkly pigmented roots, such as those of grapevines so additional steps are required to ensure clear visualisation. Three fixing and clearing processes were evaluated prior to staining with trypan blue: 1) fixing grapevine roots in $70 \% \mathrm{v} / \mathrm{v}$ ethanol overnight; 2 ) clearing by heating the roots in either $2 \%$ or $10 \% \mathrm{w} / \mathrm{v} \mathrm{KOH}$; and 3) clearing the roots in 3\% v/v hydrogen peroxide for $10 \mathrm{~min}$. Roots were examined under a compound light microscope for the presence of AMF. A combination of fixing grapevine roots in $70 \%$ ethanol overnight and clearing by autoclaving in $10 \% \mathrm{KOH}$ produced the greatest enhancement in subsequent staining of grapevine roots with trypan blue overnight. The best method tested enabled the discrimination of arbuscular mycorrhizal structures in fresh roots of grapevines without the use of toxic chemical fixatives.
\end{abstract}

Keywords pigmented roots, trypan blue, arbuscules, ethanol, potassium hydroxide, microscope, AMF

\section{INTRODUCTION}

Arbuscular mycorrhizal symbiosis originated in the early Devonian period, approximately 400 million years ago. Arbuscular mycorrhizal fungi (AMF) are obligate biotrophs that colonise the roots of their host plants and are unable to complete their life cycle without the carbon supply from their host (Bonfante \& Genre 2010). In return, the fungi supply the plant with mineral nutrients, such as phosphorus and water so this mutualistic association is based on biotrophic exchanges between the plant and the fungi (Trouvelot et al. 2015). More than $80 \%$ of all land plant families have a symbiotic interaction with AMF, including grapevines.

AMF are identified by the presence of tree-like branching hyphal structures (called arbuscules) found in the cortical cells of the host plant. Arbuscules form in root cells of the host then extraradical mycelia grow outside the roots to expand the zone in which water and nutrients can be acquired (Smith \& Read 2008). Some AMF genera/species also produce vesicles that function as nutrient stores and as propagules (Goltapeh et al. 2008). These structures provide for a very intimate association between the mycorrhizal fungi living within the host plant's root cells. Therefore, roots must be cleared of cellular contents, and the endophytic fungi stained prior to microscopic observation in order for the colonisation process and functionality of AMF symbiosis to be appropriately interpreted and understood.

Staining not only produces reliable data on the level of root colonisation but also allows the presence of key
AMF features (such as hyphae, vesicles and arbuscules) to be visualised (Brundrett 2004). It is important that root material is processed in such a way that the defining fungal features can be easily viewed to enable the examination of these morphological characteristics (Vierheilig et al. 2005). Light microscopy with bright field is the most common microscopic technique used when studying AMF structures in roots (Hulse 2018). Over the years, scientists have experimented with several different chemical stains and fixation methods, each having advantages and disadvantages for discriminating AMF from the plant root material. Some studies have used Sheaffer blue ink (Wilkes et al. 2019) or acid fuchsin (Diagne et al. 2011) for staining, however these stains proved not to be suitable for long term storage and fade with time (Vierheilig et al. 2005). Other studies have shown that both chlorazol black E and trypan blue provided good contrast from plant cells, but they are known animal (and possible human) carcinogens, which poses undesirable risks to research staff, and challenges for safe disposal of the waste materials (Grace \& Stribley 1991; Kumar et al. 2008). Trypan blue is commonly used for assessing yeast cell viability (Liesche et al. 2015) and for visualization of oomycetes (Nowicki et al. 2012) and fungi (Bhadauria et al. 2010; Mulaosmanovic et al. 2020), including Glomeromycota (Kumar et al. 2008). These studies reported that trypan blue stained the cell walls of fungal cells but not of living plant cells. Despite its carcinogenity, trypan blue is one of the most widely used stains due to its effectiveness in enabling the 
observation of mycorrhizal colonisation. Kobae \& Ohtomo (2016) reported that $57 \%$ of relevant studies published in 2014-2015 used trypan blue and therefore it was also used in the current study. The concentration of trypan blue has been reduced from $1 \%$ to $0.05 \%$ over recent years to limit its toxicity. Recently, Cottet et al. (2018) in their review of staining methods using trypan blue as a chemical stain suggested that optimisation of specific steps such fixation and clearing could affect the visibility of fungal structures in the roots.

Various processes (known as 'clearing') have been used to remove the cytoplasmic contents of plants cells to improve subsequent staining using trypan blue. Potassium hydroxide $(\mathrm{KOH})$ has been widely used as a root-clearing method with various concentrations, temperatures and periods of time employed for different plant species. For example, Kobae \& Ohtomo (2016) boiled soybean roots in 10\% (w/v) $\mathrm{KOH}$ for $15 \mathrm{~min}$, and other variations are detailed by Cottet et al. (2018). Fungal structures contained within the root cells, can be deliberately damaged using a heat treatment to allow trypan blue to enter (Wilkes et al. 2019). Fine and fibrous roots (i.e. clover and plantain roots) are easily cleared for excellent microscopic visualisation of the fungal and plant tissue. However, grapevines are hard woody plants and have thick and pigmented roots, which are very difficult to stain. Darkly pigmented roots require the inclusion of additional steps such as the use of bleaching hydrogen peroxide to enable the visualisation of AMF structures (Kormanik \& McGraw 1982; Schreiner \& Mihara 2009; Hashem et al. 2016; Padamsee et al. 2016; Vierheilig et al. 2005) and/or fixing by incubating roots in $50 \%$ ethanol (Kobae \& Ohtomo 2016) or other fixatives (e.g. FAA) to reduce the damage from heat treatment, allowing enhanced staining of intracellular fungal root components by trypan blue (Brundrett et al. 1996; Brundrett 2008; Wilkes et al. 2019).

The aim of this study was to assess a range of existing techniques to develop a reliable method specifically for fixing, clearing and staining darkly pigmented grapevine roots to enable visualisation of AMF structures in grapevine roots.

\section{MATERIALS AND METHODS}

\section{Plant materials}

AMF pot cultures were set up using grapevine (Vitis spp.) root samples collected from commercial vineyards. Grapevine root samples were collected from the vineyards in JanuaryFebruary 2017, placed in plastic bags and transported to the laboratory in a chilly bin. The roots $(0.5$ to $1 \mathrm{~g})$ were cut into $1-\mathrm{cm}$ pieces and used to inoculate $1.5 \mathrm{~L}$ plastic pots containing $50 \%$ sterile silica sand, $40 \%$ pumice and $10 \%$ low-phosphorus potting mixture (peat moss, forest bark and fertilisers: osmocote 38-0-0, osmocote 0-0-32, horticultural lime, Micromax trace elements and hydraflo soil wetting agent). Each pot was sown with plantain (Plantago lanceolata) and white clover (Trifolium repens) seeds $(0.1 \mathrm{~g}$ each; previously surface-sterilised using 70\% v/v ethanol) along with a grapevine rootstock cutting. The plants were placed on mesh tables in a greenhouse to grow for 12 weeks during the summer of 2018 before being dried for 2 weeks prior to being used to assess the different protocols for fixing, clearing and staining of the roots for visualisation of mycorrhizal colonisation. Plantain and white clover were included as bait plants were used as positive controls for the staining treatments as they are considered easy to stain (https://invam.wvu.edu).

\section{Fixing, clearing and staining of grapevine roots}

Initially, attempts to visualise AMF colonisation in the grapevine roots collected from the vineyards was carried out using a modification of the method outlined by Brundrett (1996) for herbaceous plants, with outline of the method described later for AMF colonisation assessment of plantain and white clover (Table 1). However, due to the root pigmentation and background staining, observations of AMF structures were difficult to distinguish from plant cells.

In autumn 2018, root samples from the grapevine plants from the pot cultures were randomly selected for each staining treatment. Twelve treatments based on the protocols of Koske \& Gemma (1989) and Brundrett (1996) were evaluated (as shown in Table 1) to confirm mycorrhizal colonisation. The collected roots were washed using tap water to remove debris and a small portion $(\sim 4 \mathrm{~cm})$ of the roots placed in a Universal bottle.

\section{Fixing}

For those treatments that included a fixing step, roots were covered with $70 \% \mathrm{v} / \mathrm{v}$ ethanol $(\sim 20 \mathrm{~mL})$ as recommended by Fonseca et al. (2014) and Cottet et al. (2018) and left overnight at room temperature then decanted prior to clearing.

\section{Clearing}

Potassium hydroxide: roots for all the treatments were immersed in $20 \mathrm{~mL}$ aqueous potassium hydroxide $(\mathrm{KOH})$ solution (either $2 \%$ or $10 \% \mathrm{w} / \mathrm{v}$ ) and autoclaved in a pressure cooker (15 $\mathrm{min}, 121^{\circ} \mathrm{C} ; 15$ p.s.i.). The $\mathrm{KOH}$ was then decanted.

Hydrogen peroxide: some treatments included a second clearing step where the roots were treated with $3 \%$ hydrogen peroxide $\left(\mathrm{H}_{2} \mathrm{O}_{2}\right)$ for $30 \mathrm{~min}$ at room temperature, rinsed thoroughly with deionised water $\left(\mathrm{dH}_{2} \mathrm{O}\right)$.

All treatments were acidified in $2 \%(\mathrm{v} / \mathrm{v}) \mathrm{HCl}(12 \mathrm{M})$ for $30 \mathrm{~min}$.

\section{Staining}

All previously treated roots were stained using trypan blue $(0.05 \% \mathrm{w} / \mathrm{v}$ dissolved in a solution of $5 \%$ lactic acid, 50\% glycerol and 45\% water). Half the treatments involved autoclaving for $15 \mathrm{~min}$ in a pressure cooker and the other half were left overnight at room temperature (Table 1). Following staining, the roots were de-stained using lactoglycerol (1:1:1 lactic acid: glycerol: water) for long-term storage at $4^{\circ} \mathrm{C}$ prior to microscopic observation.

Fixing, clearing and staining of plantain and white clover The treatment used for plantain and white clover roots was a modification of the method outlined by Koske \& Gemma (1989). Fixing involved storing 1-cm root pieces 
Table 1 Details of the fixing, clearing and staining treatments used in the current study for grapevine roots and those in relevant references

\begin{tabular}{|c|c|c|c|c|c|c|}
\hline \multirow[t]{3}{*}{ Treatments } & \multirow{3}{*}{$\begin{array}{c}\text { Fixing } \\
\text { 70\% Ethanol } \\
\text { (overnight) }\end{array}$} & \multicolumn{3}{|c|}{ Clearing } & \multicolumn{2}{|r|}{ Staining } \\
\hline & & \multicolumn{2}{|c|}{$\begin{array}{c}\text { KOH } \\
\text { (Autoclave; } 15 \text { min) }^{1}\end{array}$} & $\begin{array}{c}\mathrm{H}_{2} \mathrm{O}_{2} \\
(10 \mathrm{~min})^{1}\end{array}$ & $\begin{array}{c}\text { Autoclave } \\
\text { (15 min) }\end{array}$ & $\begin{array}{l}\text { Room temperature } \\
\text { (overnight) }\end{array}$ \\
\hline & & $2 \%$ & $10 \%$ & $3 \%$ & & \\
\hline Koske \& Gemma 1989 & $\mathrm{X}$ & $\mathrm{X}^{2}$ & - & - & - & $\mathrm{X}$ \\
\hline Brundrett 1996 & - & - & $\mathrm{X}$ & 3 & $\mathrm{X}$ & - \\
\hline 1 & - & $\mathrm{X}$ & - & - & $\mathrm{X}$ & - \\
\hline 2 & - & $\mathrm{X}$ & - & - & - & $\mathrm{X}$ \\
\hline 3 & - & - & $\mathrm{X}$ & - & $\mathrm{X}$ & - \\
\hline 4 & - & - & $\mathrm{X}$ & - & - & $\mathrm{X}$ \\
\hline 5 & - & $\mathrm{X}$ & - & $\mathrm{X}$ & $\mathrm{X}$ & - \\
\hline 6 & - & $\mathrm{X}$ & - & $\mathrm{X}$ & - & $\mathrm{X}$ \\
\hline 7 & - & - & $\mathrm{X}$ & $\mathrm{X}$ & $\mathrm{X}$ & - \\
\hline 8 & - & - & $\mathrm{x}$ & $\mathrm{X}$ & - & $\mathrm{X}$ \\
\hline 9 & $\mathrm{X}$ & $\mathrm{X}$ & - & - & $\mathrm{X}$ & - \\
\hline 10 & $\mathrm{X}$ & $\mathrm{X}$ & - & - & - & $\mathrm{X}$ \\
\hline 11 & $\mathrm{X}$ & - & $\mathrm{X}$ & - & $\mathrm{X}$ & - \\
\hline 12 & $\mathrm{X}$ & - & $\mathrm{X}$ & - & - & $\mathrm{X}$ \\
\hline
\end{tabular}

${ }^{1}$ except where other conditions are noted

${ }^{2}$ Boiled for $10 \mathrm{~min}$.

${ }^{3} 0.5 \% \mathrm{NH}_{4} \mathrm{OH}$ and $0.5 \% \mathrm{H}_{2} \mathrm{O}_{2} \mathrm{v} / \mathrm{v}$ in water for varying lengths of time.

in $70 \%$ ethanol overnight then clearing by immersing in boiling $2 \% \mathrm{KOH}$ for $10 \mathrm{~min}$. Roots were then acidified in $2 \%(\mathrm{v} / \mathrm{v}) \mathrm{HCl}$ for $15 \mathrm{~min}$ and then stained overnight in $0.05 \%$ trypan blue solution as described above. Finally, the roots were de-stained in lactoglycerol and stored for $24 \mathrm{~h}$ before microscopic observation.

\section{Microscopic observation}

Root fragments (3-cm long) from each plant species were placed on a microscope slide with a drop of lactoglycerol $24 \mathrm{~h}$ after de-staining. The roots were pressed gently onto the slide using a cover slip in order to flatten the roots to improve microscopic visualisation. The root fragments were then assessed by observing under a microscope $(\times 400$ magnification; 10X ocular/40X) to determine the efficiency of the clearing and staining treatments and assessed for the presence of visible AMF structures (e.g. arbuscules, hyphae and vesicles). Observations were undertaken on triplicate samples.

\section{Confirmation of method using vineyard sampled grapevine roots}

The best method determined in the study was tested for effective staining of vineyard sourced grapevine roots.

\section{RESULTS}

Ten of the twelve methods tested resulted in stained grapevine roots that, when examined microscopically, demonstrated the presence of various structures typical of AMF such as aseptate hyphae, arbuscules and vesicles (Figure 1). The results from treatments 1 and 3 (using either $2 \%$ or $10 \% \mathrm{KOH}$ followed by staining for $15 \mathrm{~min}$ in an autoclave) did not produce visible images so were not included in Figure 1. Staining overnight at room temperature caused the surrounding plant cells to be stained, and a range of different colours was observed which made it very difficult to distinguish between plant and fungal structures (Figure 1, treatments 2 and 4). Treatments 5-8 that involved an additional step using $3 \% \mathrm{H}_{2} \mathrm{O}_{2}$ were not efficient in clearing the roots. The use of $2 \% \mathrm{KOH}$ did not result in sufficient clearing of the pigmented grapevine roots with root tissue also staining blue, resulting in little contrast and creating a poor image for visualisation of AMF structures (Figure 1, treatments 5 and 6). The use of $10 \% \mathrm{KOH}$ instead of $2 \%$ improved the root clearing (Figure 1, treatments 7 and 8). However, fixing the roots in $75 \%$ ethanol overnight prior to the start of the clearing and staining process greatly improved the clearing of the plant cell background and the AMF structures were more apparent and distinguishable from the plant tissue (Figure 1, treatments 9-12). Overnight staining (Figure 1, treatments 6, 8, 10 and 12) provided better results than staining by autoclaving for $15 \mathrm{~min}$ (Figure 1, treatments 5, 7, 9 and 11). Clear staining was observed for clover and plantain using the standard published method. Dark septate endophytes (DSE) were observed in plantain roots (Figure 1a), but not in clover (Figure 1c) or grapevine roots. 

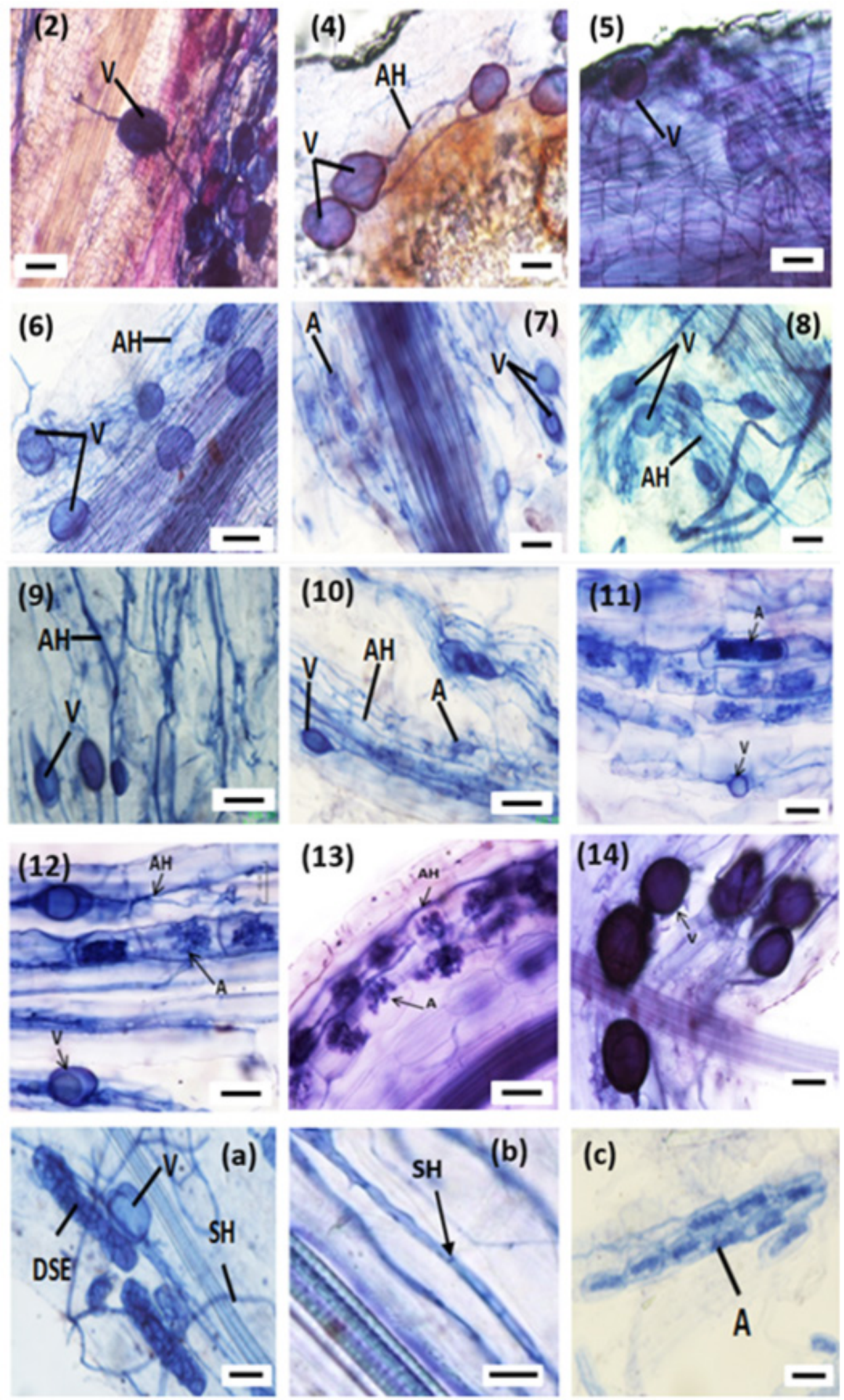

Figure 1 Typical colonisation of plant roots from trap cultures visualised under a compound microscope (400x). AMF colonisation in grapevine roots after clearing and staining using 10 out of 12 different treatments listed in Table 1. The number on each figure represents the number the treatment, as described in Table 1. (13) and (14) Vineyard sourced grapevine roots stained using method 12 from Table 1. A: arbuscules; AH: aseptate hyphae; V: vesicles (a) AMF and dark septate endophyte colonisation in plantain roots, DSE: dark septate endophyte, SH: septate hyphae; V: vesicles. (b) Septate hyphae in plantain roots. (c) AMF colonisation in white clover roots. A: arbuscules. The scale bar represents $100 \mu \mathrm{m}$. 
The best method (treatment 12) was also shown to result in clear visualisation of AMF structures in vineyard sourced grapevine roots (Figure 1,13 and 14).

\section{DISCUSSION}

The clearest assessment of AMF colonisation in grapevine roots was from roots fixed in $70 \%$ ethanol overnight followed by clearing the roots by autoclaving in $10 \%$ potassium hydroxide for 15 min followed by staining with trypan blue overnight at room temperature. This method will be used for analysing AMF colonisation in future glasshouse and vineyard experiments with grapevines. This method had also been recently tested and shown to be effective for staining AMF colonising apple roots (Merriam Toalak, pers. comm.). The standard method of Koske \& Gemma (1989) was effective for observation of AMF colonisation of roots of herbaceous, fibrous plantain and white clover roots. As reported by Brundrett (2008), the process is strongly influenced by plant species and root thickness and different root types require different methods to enable the imaging of AMF features in the roots to be clearly seen.

In this study, root clearing was carried out by autoclaving in presence of $\mathrm{KOH}$ (at two different concentrations) at $121^{\circ} \mathrm{C}$ (at 15 p.s.i.) since it has been reported to be faster and to provide a more consistent clearing of samples (Bevege 1968, Brundrett et al. 1984) than other methods such as incubation in hot water $\left(80^{\circ} \mathrm{C}\right)$ or in an oven $\left(60^{\circ} \mathrm{C}\right)$. It was also evident in the present work that treatment with $10 \% \mathrm{KOH}$ at $121^{\circ} \mathrm{C}$ improved the clearing of the roots compared to the use of $2 \%$ $\mathrm{KOH}$. This agreed with the observations of Brundrett (1984), Brundrett et al. (1996) and Oliveira et al. (2009). However, after staining in trypan blue, the AMF structures within the roots were not clear due to background staining, which was probably due to the presence of remaining plant cytoplasm and secondary metabolites (Vierheilig et al. 2005). Moreover, the trypan blue stain can bind to phenolic compounds such as melanins in plant cell walls as well as hyphal walls (Brundrett et al. 1984). AMF structures were clearer in roots when a $3 \%$ hydrogen peroxide bleaching step was added following $10 \% \mathrm{KOH}$. However, bleaching with hydrogen peroxide did not remove the remaining melanin in cleared grapevine roots, similar to reports by Oliveira et al. (2009). Higher concentrations of $\mathrm{H}_{2} \mathrm{O}_{2}$ may have increased transparency but were not tested in the current study, as it has been reported by Vierheilig et al. (2005) to cause the disintegration of fungal hyphae in the tissue. In order to clear the background from any phenolic-like materials, the roots were immersed in $70 \%$ ethanol overnight for fixation prior to the clearing process as this has been reported to cause a partial decolourisation that dehydrates the cells which allow a greater penetration of the $\mathrm{KOH}$ (Cottet et al. 2018). Incubating the roots in ethanol increased the subsequent penetration of the root tissue by potassium hydroxide and eliminated all unwanted background staining resulting in AMF structures being clearly visible to enable quantification. From the results of this study, staining the roots with a weak trypan blue solution $(0.05 \%)$ overnight is recommended as it provided better results than staining by autoclaving in $0.05 \%$ solution while reducing toxicity.
All roots from the three bait plants were efficiently colonised by AMF when assessed microscopically. Moreover, we found that most assessed plantain root samples were frequently colonised by DSE. This result suggested that plantain is a potential host plant for this endophyte. Since the seeds of both plantain and white clover were surface sterilised, the source of DSE is likely to be the rhizosphere soil associated with the grapevine roots as the roots used for inoculation were washed but not sterilised. The absence of DSE colonisation in grapevine and white clover roots might have been affected by the phylogenetic features of the host plant which play an important role in colonisation (Sivakumar 2013; Liu et al. 2017). Alternatively, the lack of DSE colonisation could be related to environmental stresses (Deram et al. 2011, Varma et al. 2017) which is likely in this study as plants were exposed to high temperature (above $30^{\circ} \mathrm{C}$ ) during the summer growing period which caused stress and death of some vines. The co-occurrence of AMF and DSE has been reported before in many plant roots and it was suggested that both endophytes provide similar ecological services such as heavy metal stress mitigation and improving plant fitness and physiology (Wang et al. 2016; Gucwa-Przepióra et al. 2016; Likar \& Regvar 2013). Whether DSEs are able to colonise grapevine roots under New Zealand vineyard conditions is unclear and warrant further study.

\section{CONCLUSIONS}

Arbuscular mycorrhizal fungi are beneficial fungi colonising most vascular plants. Imaging and assessing root tissues for visible AMF structures can be challenging when using dark pigmented roots of hard woody plants like grapevine. The inclusion of an initial fixative step involving the use of $70 \%$ ethanol followed by clearing by autoclaving in $10 \%$ potassium hydroxide improved clearing of these roots prior to staining overnight in $0.05 \%$ trypan blue resulting in enhanced observations of AMF structures and improved visualisation capability without the use of toxic fixatives such as glacial acetic acid or formaldehyde.

\section{ACKNOWLEDGEMENTS}

This work was funded by Plant and Food Research (Strategic Science Investment Fund) and Lincoln University, New Zealand. Root materials from vineyards were sampled with the help of Dion Mundy, Plant and Food Research Marlborough, Sandy Hammond and Myles Mackintosh, Lincoln University. Grapevine cuttings for pot cultures were provided by Corbans Nurseries. The authors are also grateful to the Lincoln University Nursery staff for maintaining the pot experiments.

\section{REFERENCES}

Bevege D 1968. A rapid technique for clearing tannins and staining intact roots for detection of mycorrhizas caused by Endogone spp., and some records of infection in Australasian plants. Transactions of the British Mycological Society 51: 808-810. https://doi.org/10.1016/S0007- 


\section{6(68)80106-8}

Bhadauria V, Miraz P, Kennedy R, Banniza S, Wei Y 2010. Dual trypan-aniline blue fluorescence staining methods for studying fungus-plant interactions. Biotechnic and Histochemistry 85: 99-105. https://doi. org/10.3109/10520290903132196

Bonfante P, Genre A 2010. Mechanisms underlying beneficial plant-fungus interactions in mycorrhizal symbiosis. Nature Communication 1: 48. https://doi.org/10.1038/ ncomms 1046

Brundrett MC 2004. Diversity and classification of mycorrhizal associations. Biological Review 78: 473-495. https://doi. org/10.1017/S1464793103006316

Brundrett M 2008. Clearing and Staining Mycorrhizal Roots. Retrieved on 28 May 2019 from https://mycorrhizas. info/method.html\#clear

Brundrett M, Bougher N, Dell B, Grove T, Malajczuk N 1996. Working with Mycorrhizas in Forestry and Agriculture. ACIAR Monograph 32. Australian Centre for International Agricultural Research, Canberra, Australia.

Brundrett MC, Piche' Y, Peterson RL 1984. A new method for observing the morphology of vesicular-arbuscular mycorrhizae. Canadian Journal of Botany 62: 2128-2134. https://doi.org/10.1139/b84-290

Cottet AC, Scervino JM, Messuti MI 2018. An improved staining protocol for the assessment of arbuscular mycorrhizal in bryophytes. Boletín de la Sociedad Argentina de Botánica 53: 201-206. https://doi.org/10.31055/1851.2372.v53. $\underline{\mathrm{n} 2.20577}$

Deram A, Languereau-Leman F, Haluwyn CV 2011. Mycorrhizal and endophytic fungal colonization in Arrhenatherum elatius L. roots according to the soil contamination in heavy metals. Soil and Sediment Contamination 20: 114127. https://doi.org/10.1080/15320383.2011.528470

Diagne N, Escoute J, Lartaud M, Verdeil JL, Franche C, Kane A, Bogusz D, Diouf D, Duponnois R, Svistoonoff S 2011. Uvitex2B: a rapid and efficient stain for detection of arbuscular mycorrhizal fungi within plant roots. Mycorrhiza 21(4): 315-321. https://doi.org/10.1007/s00572-0100357-8

Fonseca HMAC, Berbera RL, Pereira ML 2014. Monoxenic cultures of light sensitive arbuscular mycorrhizal fungi with Lunularia cruciata (Marchantiopsida). Nova Hedwigia 98: 79-87. https://doi.org/10.1127/0029$\underline{5035 / 2013 / 0147}$

Goltapeh EM, Danesh YR, Prasad R, Varma A 2008. Mycorrhizal fungi: What we know and what should we know? In: Varma A, Ed. Mycorrhiza. 3rd ed. Berlin Heidelberg: SpringerVerlag. Pp. 3-27. https://doi.org/10.1007/978-3-54078826-3 1

Grace C, Stribley DP 1991. A safer procedure for routine staining of vesicular-arbuscular mycorrhizal fungi. Mycological Research 95(10): 1160-1162. https://doi. org/10.1016/S0953-7562(09)80005-1

Gucwa-Przepióra E, Nadgórska-Socha A, Fojcik B, Chmura D 2016. Enzymatic activities and arbuscular mycorrhizal colonization of Plantago lanceolata and Plantago major in a soil root zone under heavy metal stress. Environmental Science and Pollution Research 23(5): 4742-4755. https:// doi.org/10.1007/s11356-015-5695-9
Hashem A, Alterami SA, Alqarawi AA, Abd-Allah EF, Egamberdieva D 2016. Arbuscular mycorrhizal fungi enhance basil tolerance to salt stress through improved physiological and nutritional status. Pakistan Journal of Botany 48: 37-46.

Hulse J D 2018. Review of comprehensive staining techniques used to differentiate Arbuscular Mycorrhizal fungi from plant root tissues. Acta Scientific Agriculture 2.7: 39-44.

Kobae Y, Ohtomo R 2016. An improved method for bright-field imaging of arbuscular mycorrhizal fungi in plant roots. Soil Science and Plant Nutrition. 62: 27-30. https://doi.org/1 $\underline{0.1080 / 00380768.2015 .1106923}$

Kormanik PP, McGraw AC 1982. Quantification of vesicular arbuscular mycorrhizae in plant roots. In: Schenck NC (Eds). Methods and Principles of Mycorrhizal Research. The American Phytopathological Society, St. Paul. Pp. 3745.

Koske RE, Gemma JN 1989. A modified procedure for staining roots to detect VA mycorrhizas. Mycological Research 92: 486-505. https://doi.org/10.1016/S09537562(89)80195-9

Kumar T, Majumdar A, Das P, Sarafis V, Ghose M 2008. Trypan blue as a fluorochrome for confocal laser scanning microscopy of arbuscular mycorrhizae in three mangroves. Biotechnic and Histochemistry 83.3-4: 153-159. https:// doi.org/10.1080/10520290802336161

Liesche J, Marek M, Gunther-Pomorski T 2015. Cell wall staining with Trypan blue enables quantitative analysis of morphological changes in yeast cells. Frontiers in Microbiology 6. https://doi.org/10.3389/ fmicb.2015.00107

Likar M, Regvar M 2013. Isolates of dark septate endophytes reduce metal uptake and improve physiology of Salix caprea L. Plant and Soil 370: 593-604. https://doi. org/10.1007/s11104-013-1656-6

Liu H, Li T, Ding Y, Yang Y, Zhao Z 2017. Dark septate endophytes colonizing the roots of 'non-mycorrhizal' plants in a mine tailing pond and in a relatively undisturbed environment, Southwest China. Journal of Plant Interactions 12(1): 264-271. https://doi.org/10.1080/17429145.20 $\underline{17.1333635}$

Mulaosmanovic E, Lindblom T, Bengtsson M, Windstam ST, Mogren L, Marttila S, Stützel H, Alsanius BW 2020. High-throughput method for detection and quantification of lesions on leaf scale based on trypan blue staining and digital image analysis. Plant Methods 16: 62. https://doi. org/10.1186/s13007-020-00605-5

Nowicki M, Lichocka M, Nowakowska M, Kłosińska U, Kozik EU 2012. A simple dual stain for detailed investigations of plant-fungal pathogen interactions. Vegetable Crops Research Bulletin 77: 61-74. https://doi.org/10.2478/ v10032-012-0016-z

Oliveira CA, Sa NMH, Gomes EA, Marriel IE, Scotti MR, Guimaraes CT, Schaffert RE, Alves VMC 2009. Assessment of the mycorrhizal community in the rhizosphere of maize (Zea mays L.) genotypes contrasting for phosphorus efficiency in the acid savannas of Brazil using denaturing gradient gel electrophoresis (DGGE). Applied Soil Ecology 41(3): 249-258. https://doi.org/10.1016/j. apsoil.2008.11.005 
Padamsee M, Johansen RB, Stuckey SA, Williams SE, Hooker JE, Burns BR, Bellgard SE 2016. The arbuscular mycorrhizal fungi colonising roots and root nodules of New Zealand kauri Agathis australis. Fungal Biology 120 (5): 807-817. https://doi.org/10.1016/j.funbio.2016.01.015

Sivakumar N 2013. Effect of edaphic factors and seasonal variation on spore density and root colonization of arbuscular mycorrhizal fungi in sugarcane fields. Annals of Microbiology 63:151-160. https://doi.org/10.1007/ s13213-012-0455-2

Smith SE, Read DJ 2008. Mycorrhizal symbiosis, 3rd ed. London, UK: Academic Press.

Schreiner RP, Mihara KL 2009. The diversity of arbuscular mycorrhizal fungi amplified from grapevine roots (Vitis vinifera L.) in Oregon vineyards is seasonally stable and influenced by soil and vine age. Mycologia 101: 599-611. https://doi.org/10.3852/08-169

Trouvelot S, Bonneau L, Redecker D, van Tuinen D, Adrian M, Wipf D 2015. Arbuscular mycorrhiza symbiosis in viticulture: a review. Agronomy for sustainable Development. 35: 1449-1467. https://doi.org/10.1007/ s13593-015-0329-7

Varma A, Prasad R, Tuteja N. (Eds.) 2017. Mycorrhiza-Function, Diversity, State of the Art. https://doi.org/10.1007/9783-319-53064-2

Vierheilig H, Schweiger P and Brundrett M 2005. An overview of methods for the detection and observation of arbuscular mycorrhizal fungi in roots. Physiologia Plantarum 125: 393-404. $\quad$ https://doi.org/10.1111/j.13993054.2005.00564.x

Wang J, Li T, Liu G, Smith JM, Zhao Z 2016. Unraveling the role of dark septate endophyte (DSE) colonizing maize (Zea mays) under cadmium stress: physiological, cytological and genic aspects. Scientific Reports 6: 22028. https://doi. org/10.1038/srep22028

Wilkes TI, Douglas JW, Veronica EB, Davis KG, Denholm I Warner D, Edmonds B, 2019. A comparison of methodologies for the staining and quantification of intracellular components of arbuscular mycorrhizal fungi in the root cortex of two varieties of winter wheat. Access Microbiology 2. https://doi.org/10.1099/ acmi. 0.000083 